\title{
A multi-scale simulation of vinyl acetate systems applied in the industrial gas separation column
}

\author{
Minhua Zhang ${ }^{1}$, Lihang $\mathrm{Chen}^{1}$, and Jing $\mathrm{Ma}^{2}$ \\ ${ }^{1}$ Affiliation not available \\ ${ }^{2}$ Tianjin University
}

June 25, 2020

\begin{abstract}
In this work we focus on the separation of the key component vinyl acetate (VAc) and the light components acetylene (C2H2), carbon dioxide $(\mathrm{CO} 2)$ and acetaldehyde $(\mathrm{CH} 3 \mathrm{CHO})$ in the VAc synthesis process. The vapor-liquid phase equilibrium (VLE) data were calculated for the binary systems C2H2-VAc, CO2-VAc and CH3CHO-VAc with Gibbs Ensemble Monte Carlo (GEMC) simulation, in which the force field parameters were obtained by the quantum chemistry and parameters fitting method. The binary interaction parameters of UNIQUAC thermodynamic models with Henry's law were determined by fitting the equilibrium data, and applied for the process modeling of the industrial gas separation column. The consistency between the calculation results and the industrial installation data confirmed the accuracy of the fitted thermodynamic model. This work developed a new way from microscopic GEMC simulations to macro process modeling for the system without VLE experiment data.
\end{abstract}

\section{Hosted file}

Manuscript.docx available at https://authorea.com/users/336917/articles/462586-a-multiscale-simulation-of-vinyl-acetate-systems-applied-in-the-industrial-gas-separationcolumn 


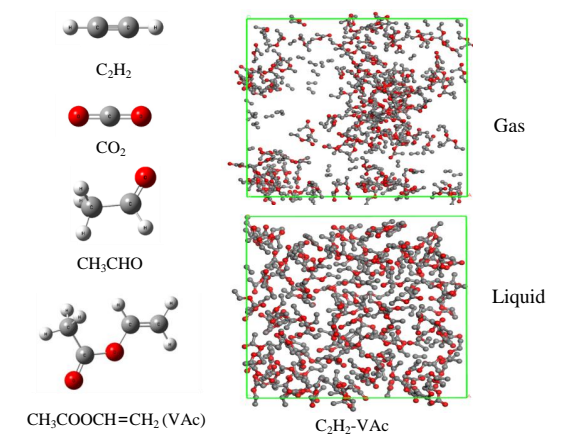

Figure 1. Molecular structures and equilibrium configuration of gas/liquid phase box in GEMC simulation.

\section{Hosted file}

Table.docx available at https://authorea.com/users/336917/articles/462586-a-multi-scalesimulation-of-vinyl-acetate-systems-applied-in-the-industrial-gas-separation-column 